\title{
Synergies in Cybersecurity Incident Reporting - The NIS Cooperation Group Publication 04/20 in Context
}

\author{
Sandra Schmitz-Berndt and Fabian Anheier*
}

\section{Introduction}

A central element of EU legislative framework for cybersecurity is the reporting of security breaches. ${ }^{1}$ Mandatory reporting to national authorities promotes a culture of risk management, while also providing for the sharing of information about vulnerabilities. In this line, the GDPR ${ }^{2}$ introduced reporting obligations for data controllers based on the assumption that security challenges and relevant mitigation measures can be better identified if data breaches are communicated to public authorities. Similarly, the first horizontal cybersecurity instrument of the EU, the NIS Directive (NISD) ${ }^{3}$, introduced reporting obligations for operators of essential services and digital service providers under its scope. Little focus has been placed on the interplay of the GDPR and the NISD, in particular, as regards a duplication of reporting obligations. ${ }^{4}$ As both legal instruments apply without prejudice, in practice, the same incident may be reported to two separate regulators under different reporting schemes and notably with different objectives: in the case of GDPR the protection of personal data, in the case of NISD for the protection of the underlying infrastructure.

However, such double reporting is not restricted to the NISD and GDPR, as a variety of EU legislation en- compasses similar reporting schemes. Recently attention has been drawn to the exploitation of potential synergies by the NIS Cooperation Group, one of the cooperation mechanisms introduced by the NISD and set up under art. 11 NIS Directive in order to facilitate strategic cooperation and the exchange of information among Member States. In its CG Publication 04/20 on synergies in incident reporting, ${ }^{5}$ the NIS Cooperation Group outlined the reporting formats and procedures under different EU instruments and explored opportunities for incident reporting synergies.

This report outlines the reporting schemes under NISD and GDPR before the key findings of the CG Publication $04 / 20$ are presented. The findings are then put into context of the recent review of the NISD and the proposal for a revised NISD (NIS 2.0 proposal) ${ }^{6}$.

\section{EU Incident Reporting Schemes}

Incident reporting obligations are not novel: As regards the Telecoms (or, in EU terminology, the electronic communications networks and services) sector, ie publicly-available electronic communications and services, obligations to report security breaches exist at EU level for more than a decade. ${ }^{7}$ The CG
DOI: $10.21552 / \mathrm{edpl} / 2021 / 1 / 13$

* Sandra Schmitz-Berndt, LL.M., LL.M., is Research Associate at SnT, University of Luxembourg, working on the project EnCaViBS $(<$ https://encavibs.uni.lu/ $>$ ) with Mark Cole, for correspondence <sandra.schmitz@uni.lu>; Fabian Anheiner is student in law at the Universität Trier. The research for this article was funded by the Luxembourg National Research Fund (FNR) C18/IS/12639666/EnCaViBS/Cole, <https://www.fnr.lu/projects/the-eu-nis-directive-enhancing-cybersecurity-across-vital-business-sectors-encavibs/>.

1 NIS Cooperation Group, Annual Report NIS Directive Incidents 2019 (CG Publication 03/2020), available at <https://ec.europa eu/newsroom/dae/document.cfm?doc_id=72146> accessed 20 March 2021, 1

2 Regulation (EU) 2016/679 of the European Parliament and of the Council of 27 April 2016 on the protection of natural persons with regard to the processing of personal data and on the free movement of such data, and repealing Directive 95/46/EC (General Data Protection Regulation) [2016] OJ L119/ 1.

3 Directive (EU) 2016/1148 of the European Parliament and of the Council of 6 July 2016 concerning measures for a high common level of security of network and information systems across the Union [2016] OJ L 194/1.

4 But cf. on this eg. Mark Cole and Sandra Schmitz, The Interplay Between the NIS Directive and the GDPR in a Cybersecurity Threat Landscape (December 31, 2019). University of Luxembourg Law Working Paper No. 2019-017, available at $<$ http://dx.doi.org/10.2139/ssrn.3512093.

5 NIS Cooperation Group, Synergies in Cybersecurity Incident Reporting (CG Publication 04/2020), available at https://ec.europa.eu/newsroom/dae/document.cfm?doc_id=72147 (accessed 20.3.2021)

6 European Commission, Proposal for a Directive of the European Parliament and of the Council on measure for a high common level of cybersecurity across the Union, repealing Directive (EU) 2016/1148 (COM(2020) 823 final).

7 Under Art. 13a(3) Directive 2002/21/EC as last amended by Directive 2009/140/EC of 25 November 2009 on a common regulatory framework for electronic communications networks and services [2002] OJ L 108/ 33(Telecom Framework Directive); restricted to publicly avalable electronic communications ser- 
Publication 04/20 seeks to reflect the diversity of EU legal instruments introducing incident reporting schemes by selecting seven policy interventions from the past decade. The selected instruments cover a variety of sectors and aim at different entities and include apart from the already mentioned NISD and GDPR: Directive (EU) 2018/1972 (EECC) ${ }^{8}$ (replacing and integrating in one code the previously existing framework for electronic communications networks and services spread across several legislative acts), Directive 2002/58/EC (ePrivacy Directive), Regulation(EU) No 910/2014 (eIDAS Regulation) 9,10, Directive (EU) 2015/2366 (PSD2 Directive) ${ }^{11}$ as well as Regulation (EU) 2017/745 (MDR) ${ }^{12}$. The reporting schemes of these interventions have in common that they are aimed to understanding (cyber-)security threats as well as identifying vulnerabilities. Exemplary and in terms of simplification, the subsequent section summarises the key aspects of incident reporting under the NISD and the GDPR, since the interplay of these instruments perfectly highlights the challenges addressed by the CG Publication $04 / 20$.

vices: Art. 4(2)Directive 2002/58/EC as last amended by Directive 2009/136/EC concerning the processing of personal data and the protection of privacy in the electronic communications sector [2002] OJ L 201/37 (ePrivacy Directive) and Commission Regulation (EU) No 611/2013 of 24 June 2013 on the measures applicable to the notification of personal data breaches under Directive 2002/58/EC of the European Parliament and of the Council on privacy and electronic communications [2013] OJ L $173 / 2$.

8 Directive (EU) 2018/1972 of the European Parliament and of the Council of 11 December 2018 establishing the European Electronic Communications Code [2018] OJ L 321/36 (EEEC).

9 Regulation (EU) No. 910/2014 of the European Parliament and of the Council of 23 July 2014 on electronic identification and trust services for electronic transactions in the internal market and repealing Directive 1999/93/EC [2014] OF L 257/73 (eIDAS Regulation).

10 Directive 2002/58/EC as las amended by Directive 2009/136/EC concerning the processing of personal data and the protection of privacy in the electronic communications sector [2002] OJ L 201/37 (ePrivacy Directive).

11 Directive (EU) of the European Parliament and of the Council of 25 November 2015 on payment services in the internal market, amending Directives 2002/65/EC, 2009/110/EC and 2013/36/EU and Regulation (EU) No 1093/2010, and repealing Directive 2007/64/EC [2015] O] L 337/35 (PSD2 Directive).

12 Regulation (EU) 2017/745 of the European Parliament and of the Council of 5 April 2017 on medical devices, amending Directive 2001/83/EC, Regulation (EC) No. 178/2002 and Regulation (EC) No 1223/2009 and repealing Council Directives 90/385/EEC 2017] OJ L 117/1 (MDR).

13 Art. 4(7) NISD

\section{Incident Reporting Under the NIS- Directive}

The NISD establishes an incident reporting framework covering the notification of significant incidents as well as requiring the implementation of security measures. As regards the obligation to report an incident (ie 'any event having an actual adverse effect on the security of' NIS) $)^{13}$, the NISD differentiates between operators of essential services $(\mathrm{OESs})^{14}$ and digital service providers (DSPs) ${ }^{15}$.

Member States shall ensure that OESs and DSPs notify, 'without undue delay,' the national competent authority $(\mathrm{NCA})^{16}$ or the computer security incident response team $(\text { CSIRT })^{17}$ of incidents having a significant impact on the continuity of the essential services they provide (in case of an OES), or incidents having a substantial impact on the provision of a digital service (in case of a DSP). ${ }^{18}$ As regards OES, Article 14(4) NISD enlists sample factors to be taken in account when determining the significance of the impact of an incident, namely: (a) the number of users affected by the disruption of the essential service; (b)

14 An OES is a public or private entity within one of the sectors enlisted in Annex II, which meets the criteria laid down in art. 5(2) NISD. Art. 5(2) NISD enlists as criteria inter alia whether the entity provides a service which is essential for the maintenance of critical societal and/or economic activities, and an incident would have significant disruptive effects on the provision of that service. These criteria resemble the definition of "critical infrastructure" in art. 2(1) ECI Directive (Council Directive 2008/114/EC of 8 December 2008 on the identification and designation of European critical infrastructures and the assessment of the need to improve their protection [2008] OJ L 345/75) with the difference that only entities depending on NIS may qualify as OESs, and thus fall within the scope of the NISD. OES must be identified as such on a national basis by Member States.

15 Annex III to the NISD lists as DSPs within the scope of the NISD only three types of services: online marketplaces, online search engines, and cloud computing services. Providers of digital services have to self-determine whether they offer services of a type listed in Annex III of the NISD in order to fall within the scope of application.

16 The NISD provides for great flexibility either to implement a centralised or decentralised approach for designation of competences at national level: A narrow majority of Member States opted to designate a single NCA, others designated several sectoral NCAs. Spain, for instance, employs a decentralised approach where the competent authority depends on whether the operator concerned is an OES or DSP (Cf. Art. 9(1) Real Decretoley 12/2018 de 7 de septiembre de seguridad de las redes y sistemas de información); the same applies to the UK, where the NCA for OES further depends on the sector concerned.

17 According to art. 9 NISD, Member States shall designate one or more CSIRTs, which may be established within a NCA and must be responsible for risk and incident handling.

18 See art. 14(3) NISD as regards OES, and art. 16(3) as regards DSP. 
the duration of the incident; (c) the geographical spread with regard to the area affected by the incident. ${ }^{19}$ The amount of leeway as to the exact rules to be adopted may result in a variety of notification requirements which do not only vary from Member State to Member State but also within sectors. The substantive freedom of choice for Member States is also reflected by the fact that the reporting time window is not harmonised. The latter also applies to DSPs; however, as regards DSPS, the Commission Implementing Regulation (EU) 2018/151 ${ }^{20}$ specifies the relevant factors to determine whether an incident has a substantial impact on the provision of the digital service. Hence, an incident is to be considered substantial if eg. more than 100 ooo users have been affected or the damage caused exceeds EUR $1,000,000 .{ }^{21}$ DSPs with multiple offices in the EU have to report incidents in the Member State where they have their main establishment, while OES report to all national authorities separately in the case of a cross-border incident.

19 Recital 27 NISD calls upon MS to take into account further factors, such as the number of users relying on that service for private or professional purposes, or in terms of the incident's impact, the time likely to elapse before the discontinuity would start to have a negative impact. In addition, according to Recital 28, different sectors may require the assessment of different factors; for instance, with regard to the energy sector, factors could include the volume or proportion of national power generated, or with regard to the health sector, the number of patients under the provider's care per year.

20 Commission Implementing Regulation (EU) 2018/151 of 30 January 2018 laying down rules for application of Directive (EU) 2016/1148 of the European Parliament and of the Council as regards further specification of the elements to be taken into account by digital service providers for managing the risks posed to the security of network and information systems and of the parameters for determining whether an incident has a substantial impact [2018] OJ L26/48.

21 Art. 4 Commission Implementing Regulation (EU) 2018/151.

22 Cf. Recital 57 NISD.

23 Member States that applied a centralised approach are inter alia: Austria, Belgium, France, and Germany.

24 Member States that applied a decentralised approach are inter alia: Czech Republic, Luxembourg, the Netherlands, and Poland.

25 European Commission, Making the most of NIS - towards the effective implementation of Directive (EU) 2016/1148 concerning measures for a high common level of security of network and information systems across the Union, COM (EU) (2017) 476 final/2.

26 Arts. 14(6) and 16(6) NISD.

27 Art. 4(12) GDPR.

28 Art. 34(3)(b) GDPR.

29 See Art. 33(3) GDPR.

30 Art. 34 GDPR; see also Recital 86.
The different level of harmonisation for treatment of OES and DSPs is based on fundamentally different services provided (with OES directly linked to physical infrastructure), and also respects that OES are identified by the individual Member States. ${ }^{22}$ As regards the addressee of incident notifications, Member States can decide to apply centralised ${ }^{23}$ or decentralised ${ }^{24}$ approaches for designation of competences at national level. ${ }^{25}$ This may result in a variety NCAs linked to specific sectors covered by the Directive. The NISD does not foresee notification of the individuals concerned by the security incident. However, where public awareness is necessary in order to prevent an incident or to deal with an ongoing incident, the NCA or CSIRT may inform the public about individual incidents. ${ }^{26}$

\section{Reporting of Data Breaches under the GDPR}

Under Articles 33 and 34 GDPR, data controllers must notify a personal data breach to the supervisory authority (DPA) within 72 hours after becoming aware of it and communicate the personal data breach to the data subject without undue delay. The GDPR defines a 'personal data breach' as 'a breach of security leading to the accidental or unlawful destruction, loss, alteration, unauthorised disclosure of, or access to, personal data transmitted, stored or otherwise processed $^{27}$. According to Article 33(1) GDPR, reporting of data breaches to the competent DPA is not necessary where the personal data breach is unlikely to result in a risk to the rights and freedoms of natural persons. The same applies where the controller has taken steps to ensure that the high risk posed to individuals' rights and freedoms is no longer likely to materialise. ${ }^{28}$ In contrast to the NISD, the GDPR also determines the information to be forwarded, such as eg the nature of the personal data breach, including where possible, the categories and approximate number of data subjects concerned and the categories and approximate number of personal data records concerned. ${ }^{29}$

Article 34 GDPR requires the controller to also communicate the breach to the affected individual without undue delay. ${ }^{30}$ In contrast to Article 33 GDPR, the notification obligation requires a high risk' for the rights and freedoms of the affected individual. The notice to individuals allows the con- 
troller to provide information on the risks encountered and to advise individuals on how to protect themselves from the potential consequences of the breach. ${ }^{31}$ Where direct communication to the individuals concerned would involve disproportionate efforts, Article 34(3)(c) GDPR permits public communication or a similar measure in an equally effective manner.

As regards data breaches with cross-border relevance, Article 6o GDPR introduces a cooperation mechanism under which the lead authority, ie. the authority in the Member State where the notifying data controller is based, exchanges information with other supervisory authorities concerned.

\section{Brief Comparison of Different Reporting Schemes}

In order to facilitate a comparison of the schemes identified, the NIS Cooperation Group examined the following characteristics: services in scope, incident definitions, notification timing, notification criteria, cross-border information sharing and annual summary reporting at EU level.

While the NISD introduces a cross-sectoral cybersecurity incident reporting scheme, in contrast Article 40 EEC, Articles 10 and 19 eIDAS Regulation, and Article 96 PSD2 have a very limited and clearly defined scope of application. Simplified, they provide for an obligation to notify (security) incidents having an actual adverse effect ${ }^{32}$ on the security of network and information systems of essential services or digital services (NISD), electronic communications networks or services (EECC), trust services (eIDAS Regulation), and payment-related services (PSD2). In order to avoid a duplication of reporting obligations, Article 1(7) NISD sets forth that where a sector-specific Union act foresees security or notification requirements of at least equivalent effect, these lex specialis provisions shall prevail. Article 96 $\mathrm{PSD} 2$ is for instance considered as more specific law to the NISD with regard to the provision of payment services by credit institutions, and thus applies instead of the corresponding provisions of Article 14 NISD. ${ }^{33}$ According to Article 1(3) NISD, the same applies regarding pre-existing sector-specific legislation, namely, the reporting schemes of the EECC framework for the electronic communications networks and services and the eIDAS Regulation.
The GDPR does not constitute a lex specialis to the NISD in the sense of Article 1(7) NISD: the GDPR applies to all data controllers and requires breach notification where personal data is at stake. Differing from that, the aforementioned schemes mandate breach notification if there is a significant disruption to the provision of the service. Thus, although the notification obligations are very similar, they are not duplications and therefore do not exclude one another.

As regards cross-border information-sharing between relevant national authorities, the NIS Cooperation Group identified respective provisions in all legislations with the EU Agency for Cybersecurity (ENISA) serving as a hub for information sharing in some instruments. ${ }^{34}$

\section{Consequences of the Coexistence of Reporting Schemes with a Focus on NISD and GDPR}

Before addressing the challenges identified by the NIS Cooperation Group, it is necessary to summarise the consequences of the co-existence of the above outlined reporting schemes. First of all, there is a variety of similar reporting schemes with a variety of competent authorities at national level, which in the case of the NISD may depend on the sector concerned. While, in theory, one may distinguish between incidents falling under the GDPR and such falling under the above outlined schemes, in practice, most security incidents will involve some personal data, meaning that the data controller will have to report these incidents to two different competent authorities.

Conflicts as well as confusion may potentially arise between supervisory authorities, if the same incident is notified by two different entities to two different authorities. One such scenario may be, where a DSP reports an incident under the NISD to the NCA, and the data controller (using a service provided by the

\footnotetext{
31 Recital 86

32 The definitions of 'incidents' vary slightly, and the PSD2 distinguishes between security incidents (as malicious actions) and operational incidents.

33 (n 25), Annex I, 37

34 (n 5), 17.
} 
DSP) to the competent DPA under the GDPR. Considering that format, content and timeframe are not necessarily identical, there is a likelihood that different authorities will receive diverging information with regard to a single incident, and as a consequence, one incident may be treated as if there were separate incidents.

The notification schemes also differ in so far as they require notification of the individuals concerned.$^{35}$ If a security incident constitutes a data breach, the data controller has to notify the data subjects concerned if the data breach is likely to result in a high risk to the rights and freedoms of natural persons in order to allow these to take the necessary precautions. Data subjects themselves should be placed in a position to prevent the risk from materialising. For another reason than protecting the rights and freedoms of a natural person, publicity of incidents under the NISD aims at (re-)establishing information security, ie. confidentiality, integrity and availability of network and information systems. As a consequence, the individual affected by a mere security incident may only be informed of the incident where public awareness is necessary in order to prevent an incident, to deal with an ongoing incident, or when, limited to DSPs, disclosure is in the public interest (cf. Articles 14(6) and 16(7) NISD).

Early disclosure of an incident may interfere with the containment and recovery of an incident. ${ }^{36}$ Hence, an entity may have an interest in suspending the notification of data subjects as required under the GDPR. ${ }^{37}$ The mitigation of the impact of a cybersecurity incident in the context of compromised personal data, may thus require the cooperation of the competent NCA and DPA. For instance, a coordinated disclosure of an incident is required where an entity first needs to analyse a current at-

\footnotetext{
35 For an analysis of the consequences of timely information of individuals for the incident response see Sandra Schmitz-Berndt and Stefan Schiffner 'Don't tell them now - or at all: Responsible disclosure of security incidents under NIS Directive and GDPR' International Review of Law, Computers \& Technology (2021) https://doi.org/10.1080/13600869.2021.1885103 accessed on 25 February 2021

36 Ibid.

37 Ibid.

38 Ibid

39 According to arts. 8 (6) and 15(4) NISD, the competent authorities 'shall cooperate' with the national DPA.

40 See (n 5) 19
}

tack to prevent further attacks and assess the full impact.

\section{Findings of the NIS Cooperation Group}

The NIS Cooperation Group starting point are the advantages of exploiting synergies, before the challenges are identified. While the Publication $04 / 20$ does not provide clear guidance, it addresses the overall potential for synergies in light of the challenges. The NIS Cooperation Group puts a focus on crosssectoral information exchange, while also addressing general cost-efficiencies and simplification of notification for the benefit of entities and authorities alike. The 'Wannacry' ransomware attack in 2017 had shown that affected organisations are not limited to one sector. Information exchange is seen as an enabler to identify cross-sector issues and trends as well as dependencies. ${ }^{38}$

\section{Challenges in Exploiting Synergies}

The identified challenges in exploiting synergies of incident reporting schemes primarily relate to lacking cooperation and information sharing between the authorities involved. While cooperation and information sharing is essential to increase cyber resilience, the NISD prescribes no mandatory cooperation and information exchange across sectors (ie. where a Member State follows a decentralised approach) or with competent authorities under sectorspecific legislation (ie. where there is lex specialis). The lack of a clear mandate to share information is however not limited to authorities handling security incidents, it also applies to information sharing with DPAs. Concerning the latter, Recital 63 NISD specifies that in the context of compromised personal data, competent authorities under the NISD 'should cooperate and exchange information on all relevant matters to tackle any personal data breaches resulting from incidents'. However, there is no further framework in place to support cooperation. ${ }^{39}$

Accordingly, information about incidents is likely to stay in 'sectoral' or 'legal silos', preventing inter alia the sharing of experience and lessons learned. ${ }^{40}$ Although not addressed as a challenge by the NIS Cooperation Group, it must also be borne in mind that 
similar issues exist with regard to cross-border information sharing.

\section{Potential for Synergies}

As regards the exploitation of possible synergies, the NIS Cooperation Group distinguishes between synergies at national level and EU level.

\section{a. Possible Synergies at National Level}

Aligning and harmonising incident reporting is seen as a major facilitator not only for compliance with reporting duties, but also for the effective handling of incidents by public authorities. ${ }^{41}$ As regards the latter, the NIS Cooperation Group also addresses the potential benefits of a single (joint) reporting platform (or an alignment of reporting tools) in terms of cost-savings and efficiencies. ${ }^{42}$ Apart from this, synergies are also considered to help authorities to 'understand better the root causes and impact across sectors; identify cross-sector issues and trends; correlate to understand cross-sector cascading effects and dependencies; harmonize and simplify incident reporting for companies; enhance cross-sector collaboration on supervision; exchange good practices about incident reporting, for example about thresholds. ${ }^{43}$

Creating these synergies however does not come without challenges with many factors depending on the particular national setting. ${ }^{44}$ The NIS Cooperation Group acknowledges that there is already some value in informal and ad-hoc information sharing; this approach, however, fails to reveal larger cyber trends and patterns. ${ }^{45}$ Structured information sharing is seen as enabling joint analysis across sectors, while a joint annual report may put cybersecurity issues in perspective. ${ }^{46}$ Joint work by national authorities on taxonomies and reporting tool may further align reporting processes. The NIS Cooperation Group also identifies potential for collaboration in other supervision areas in case of a common reporting tool. ${ }^{47}$

\section{b. Possible Synergies at EU level}

At EU level, the NIS Cooperation Group focusses on similarities of existing reporting schemes and briefly explores the potential for further alignment. As re- gards synergies between incident and data breach reporting, ie. reporting under the NISD and the GDPR, one must not lose sight of the different aims of the instruments: security and resilience of NIS infrastructure and protection of personal data. Since cybersecurity incidents often involve personal data and personal data protection also depends on efficient security measures, exchanging information could help national authorities to understand if there is an underreporting of certain types of incidents. ${ }^{48}$ Furthermore, the NIS Cooperation Group identifies potential for the exchange of aggregated and anonymised information about certain incidents, while recognising that different supervision approaches at national level may hinder information sharing. ${ }^{49}$

\section{Comment: The Whole is Greater Than the Sum of its Parts}

The position of the NIS Cooperation Group is clear: there is a substantive need for alignment and harmonising reporting obligations under different EU legislative acts. If crucial information about security incidents or personal data breaches remains in 'sectoral' or 'legal silos', this prevents the sharing of experience regarding the incident and the response as well as cross-sector analysis and aggregation. Considering that the organizational measures for information security require a structured, methodical handling of computer incidents, any effective incident response process requires a learning process to better respond to future security events. ${ }^{50}$ In fact, the NIST industry standard for incident response considers this 'lessons learned' phase as one of the most important parts of incident response as it helps in

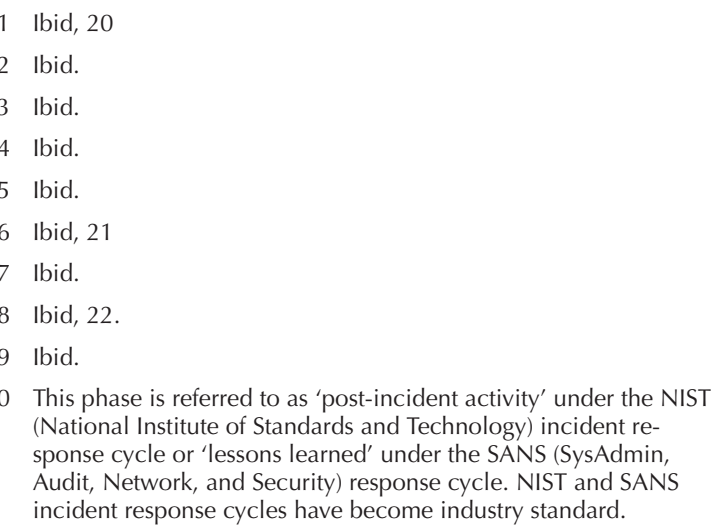


improving security measures and the incident handling process itself. ${ }^{51}$ The nature of contemporary cyber threats and attacks and the increasing dependencies on network and information systems means that coordination and information sharing about attacks becomes ever more important. Where information is collected by national authorities, these authorities are called upon to identify further affected authorities and collaborate.

The CG Publication stimulates the discussion on aligning reporting duties - an issue that has also been raised by stakeholders within the review of the NISD. During the consultation process various stakehold$\mathrm{ers}^{52}$ addressed the need for an overall cross-legislative alignment of reporting authorities, thresholds, timeframes and penalties in EU legislation to eliminate 'persisting redundancies in terms of incident reporting and double notification requirements under different legal regimes ${ }^{53} .{ }^{54}$ The NIS review is considered as a crucial opportunity to bring forth closer alignment of reporting requirements. ${ }^{55}$ Following the review of the NISD, the European Commission adopted a proposal for a revised NIS Directive on 16 December 2020 ('Proposal for NIS 2.0'). ${ }^{56}$

The NIS 2.0 proposal indeed aims to introduce a higher level of harmonisation of reporting obligations to eliminate divergences in implementation. ${ }^{57}$ The proposal also responds to the concern of fragmentation of incident reporting by including in the scope of application of the NISD providers of public electronic communications networks or publicly

51 NIST, Computer Security Incident Handling Guide, Recommendations of the National Institute of Standards and Technology (Special Publication 800-61, Revision 2, 2012), $38<$ http://dx.doi.org/10.6028/NIST.SP.800-61r2>.

52 Inter alia Microsoft, bitkom, Digitaleurope.

53 See bitkom, Roadmap NIS-Review (Position Paper, 2020), 5 $<$ https://ec.europa.eu/info/law/better-regulation/have-your-say/initiatives/12475-Cybersecurity-review-of-EU-rules-on-the-securityof-network-and-information-systems/F542104>.

54 This is in line with the responses to a consultation by the European Banking Authority with regard to its draft Guidelines on major incident reporting of 7 December 2016. Cf. EBA, Final Report on Guidelines on major incident reporting under Directive (EU) 2015/2366 (PSD2) (EBA/GL/2017/10, 2017), 12

55 Digitaleurope, Response to European Commission Roadmap on the review of EU rules on the security of network and information systems (13.08.2020), 6 <https://ec.europa.eu/info/law/betterregulation/have-your-say/initiatives/12475-Cybersecurity-reviewof-EU-rules-on-the-security-of-network-and-information-systems/F543303>.

56 (n 6) available electronic communications services, and trust service providers. The aim is to streamline the legal obligations imposed on those providers in relation to the security of their network and information systems with the obligations imposed on OES and DSPs. ${ }^{58}$ Further the respective competent authorities shall be enabled to benefit from the legal cooperation framework established by the NISD. ${ }^{59}$ The corresponding provisions laid down in the eIDAS Regulation and EECC relating to the imposition of security and reporting requirements shall be repealed. ${ }^{60}$ The NIS 2.0 proposal also contains a containment strategy in form of a two-stage approach to incident reporting in order to prevent early vulnerability disclosure when reporting an incident. ${ }^{61}$ Finally, the Proposal recognises that entities may often be in a situation where an incident needs to be reported to various authorities as a result of notification obligations included in various legal instruments. ${ }^{62}$ In order to alleviate these additional burdens and uncertainties with regard to format and procedures, Member States should establish a single joint reporting body for all notifications required under the NISD and other Union law such as in particular the GDPR. ${ }^{63}$ Such a single joint reporting body becomes ever more important in light of recently passed legislation such as the Cybersecurity $\mathrm{Act}^{64}$ and related initiatives introducing notification obligations including the proposal for the Regulation on digital operational resilience for the financial Sector (DORA) ${ }^{65}$ and the Proposal for a Directive on the resilience of critical entities ${ }^{66}$.
57 Recitals 4 and 8 NIS 2.0 Proposal.

58 Recital 48 NIS 2.0 Proposal.

59 Ibid.

60 Ibid.

61 Recital 55 NIS 2.0 Proposal.

62 Recital 56 NIS 2.0 Proposal.

63 Ibid.

64 Regulation (EU) 2019/881 of the European Parliament and of the Council of 17 April 2019 on ENISA (the European Union Agency for Cybersecurity) and on information and communications technology cybersecurity certification and repealing Regulation (EU) No 526/2013 [2019] OJ L 151/ 15

65 European Commission, Proposal for a Regulation of the European Parliament and of the Council on digital operational resilience for the financial sector and amending Regulations (EC) No 1060/2009, (EU) No 648/2012, (EU) No 600/2014 and (EU No 909/2014) (COM(2020) 595 final).

66 European Commission, Proposal for a Directive of the European Parliament and of the Council on the resilience of critical entities (COM(2020) 829 final). 